DOI: $10.14451 / 1.171 .106$

\title{
ПСИХОЛОГИЧЕСКАЯ МИНИЭКОНОМИКА РАЗВИВАЮЩЕГО ОБУЧЕНИЯ СПОРТИВНЫХ МЕНЕДЖЕРОВ КАК НАУЧНАЯ ПРОБЛЕМА
}

\author{
(C) 2019 Попова Елена Александровна \\ доктор экономических наук, доцент \\ Южно-Уральский государственный университет (Национальный Исследовательский Университет) \\ 454080, Россия, г. Челябинск, пр. Ленина, 76 \\ E-mail: 73519045153@yandex.ru; \\ (c) 2019 Базелюк Владимир Васильевич \\ доктор педагогических наук, профессор \\ Южно-Уральский государственный университет (Национальный Исследовательский Университет) \\ 454080, Россия, г. Челябинск, пр. Ленина, 76 \\ E-mail: bazeluk_vladimir@mail.ru \\ (c) 2019 Демин Александр Алексеевич \\ кандидат экономических наук, \\ Южно-Уральский государственный университет (Национальный Исследовательский Университет) \\ 454080, Россия, г. Челябинск, пр. Ленина, 76 \\ E-mail:deminaa@susu.ru
}

Представлены основные положения диалектико-материалистической теории психологической миниэкономики развивающего обучения спортивных менеджеров. Классифицированы методы, рекомендуемые для исследования научной проблемы, которая по своему содержанию является многоаспектной и «вечной» с позиций поднимаемых вопросов в рамках экономики образования. Особое внимание уделено алгоритмическому представлению психологической миниэкономики развивающего обучения и учебной деятельности вуза физической культуры.

Ключевые слова: образование, общение, мышление, развивающее обучение, миниэкономика, психология личности, ведущая деятельность, спортивный менеджент.

Введение. За годы, прошедшие с начала социально-экономических трансформаций России, трудно назвать какую-либо науку, которая могла бы считаться столь же актуальной, как психологическая экономика. Это объясняется рядом причин, в том числе возникновением множества вопросов, ответы на которые ожидаются практиками-экономистами от специалистов именно этой науки. [5]. Об одном из таких вопросов и идет речь в данной работе, посвященной психологической миниэкономике развивающего обучения спортивных менеджеров в вузе физической культуры.

Степень исследования. Проблема развивающего обучения в нашей стране разрабатывалась довольно давно, начиная - по сути - с послереволюционного периода. В то же время, интенсивность отмеченного приходится на современный отрезок времени, связанный с Болонским процессом развития обучения в вузах физической культуры. Основной подход в этом процессе мы связываем с развитием психоло- гической экономики на миниуровне - уровне мыслительной деятельности будущих спортивных менеджеров в системе «студент - преподаватель» вуза физической культуры.

Современные исследования проводятся в рамках формирующего эксперимента. Однако наибольшую значимость имеет обобщение опыта подготовки спортивных менеджеров на выпускающих кафедрах университетов сферы ФКиС национальной экономики.

Методологический аспект исследования связан с исследованиями мыслительных процессов обучающихся Д.Б. Эльконина, В.В. Давыдова, Л.В. Заикова, Л.С. Выготского, П.Я. Гольперина, Э.В. Ильенкова, С.Л. Рубинштейна и др. Особое внимание в их трудах уделялось мыслительным действиям, осуществляемым в процессе рефлексии, содержательного анализа и планирования новообразований в подготовке спортивных менеджеров.

Результаты исследования. Психологическую экономику позиционируют как «пове- 
денческую экономику». Основным методом исследования этой науки является абстрактно-дедуктивный метод (с учетом его коррекции вариативностью индивидуального экономического поведения). Основное направление движения - от построения теоретических концепций к практике (С.В. Малахов).

Таким образом, сущностное представление поведенческой экономики вытекает непосредственно из нужд теории развития хозяйствующих субъектов микроуровня. Задача этой науки - исследовать практические причины несоответствия поведения «личности» с позиции психологии ее поведения в различных ситуациях жизнедеятельности.

Моделирование при этом играет важную роль, причем не с позиции независимости хозяйствующего субъекта, а от других действующих на рынке субъектов. При этом важен учет того, что рациональность (а следовательно, обладание полной информацией в ситуациях выбора решений на поле «покупатель - продавец») подвергается сомнению. Данное обстоятельство касается наличия и других допущений, определяющих суть моделирования в рамках «поведенческой экономики».

Одно из этих допущений - максимизирующее поведение. На него «разрушающим образом» влияет эффект насыщения (Т. Синтовски). На стадии новизны экономической деятельности мотивация ускоренно возрастает с ростом стимула, а на этапе комфорта - замедляет рост (далее следует эффект насыщения).

Подвергается сомнению и другое допущение «классической модели личностного поведения на рынке товаров и услуг», а именно - экономический эгоизм. Его неэффективность опровергает М. Шериф наличием в современных условиях рыночной экономики коллективного действия и влияния. Им сформулирована концепция достижения экстраординарных целей, когда некоторые сверхцели могут быть достигнуты только в результате психологического взаимодействия субъектов и готовности пожертвовать личной выгодой и групповым фаворитизмом.

По мнению американских психологов, механизм принятия решения человеком включает фактор психологической инерции или субъективных представлений об экономической реальности, которые, прежде всего, складываются на принятии решений субъектом экономической деятельности. Он руководствуется не теоретическими положениями экономических наук, а своими представлениями об экономической реальности, которые могут значительно отклоняться от экономических расчетов (Р. Льис, Д. Майерс, Х. Райфа). При определенной точке равновесия - дополнительный прирост затрат (в том числе и психологических) на обдумывание ведет лишь к ухудшению результата.

Мы в нашей работе речь ведем об эффектах и феномене экономического поведения (его механизмах, закономерностях, алгоритмах и моделях, описывающих экономические предпочтения в сфере образования личности). Речь также идет о решениях и факторах, влияющих на эти предпочтения, а также экономическом сознании делающей выбор личности:

- экономические эмоции, окрашивающие данный выбор (практические, гностические, альтруистические, эгоистические и глорические, определяемые желанием признания);

- научное мышление и представление о том, как функционирует экономика вообще и миниэкономика развивающего обучения, в частности. Важно также: осознание сущности, усвоения и соотнесения социально-психологических понятий, категорий, теорий с требованиями экономических законов, с реальностью (тем, чтобы строить свою физкультурно-спортивную или оздоровительную деятельность в перспективе); восприятие денег, отношение к вещам и услугам с позиций как их потребителя, так и производителя.

На рисунке 1 представлены основные методы исследований в психологической миниэкономике развивающего обучения. Это эмпирические, организационные, экспериментальные и психодиагностические методы.

На другом рисунке (рисунок 2) дано алгоритмическое представление психологической миниэкономики развивающего обучения как научной проблемы. Последовательно выделено три блока: психологическая экономика образования как наука; социокультурный подход к разрешению психологических проблем экономики образования; рыночное поведение в психологической экономике образования. Последний блок посвящен перспективам развития данной научной проблемы. Прежде всего, это касается психологического портрета личности спортивного менеджера в образовании и экономического поведения на рынке труда тех, кто обучался в вузе физической культуры. 


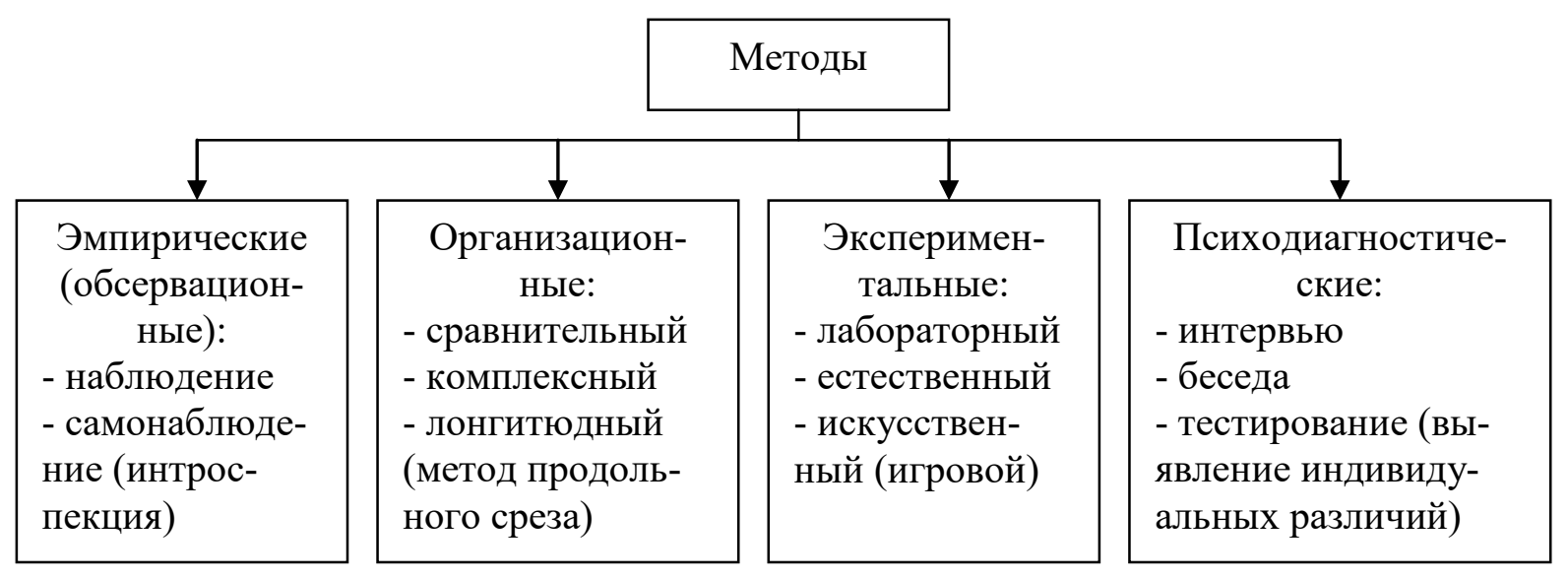

Puc. 1. Методы исследований в психологической миниэкономике развивающего обучения

1. Психологическая миниэкономика развивающего обучения как научная проблема:

- методы исследований

- представление о норме

- объект и предмет исследования

- эволюция психологических идей о миниэкономике развивающего обучения

- разделенность и неразделенность экономического и психологического знания в сфере миниэкономики развивающего обучения

2. Социокультурный подход к разрешению психологических проблем миниэкономики развивающего обучения:

- предпосылки и принципы данного похода

- психологические детерминанты личностного поведения

- психология поведения с позиций религиозных воззрений

- современные ценностные постулаты психологической миниэкономики развивающего обучения

3. Рыночное поведение в психологической миниэкономике развивающего обучения:

- общие проблемы психологии денег

- мотивы и стимулы экономического поведения в системе образования

- социокультурные стереотипы и их интерпретация

- психологический портрет личности спортивного менеджера в образовательном процессе вуза физической культуры

- инновационное поведение на миниуровне

- психология экономического поведения на рынке труда спортивных менеджеров

- структурное представление научного мышления в сфере психологии миниэконо-

мики развивающего обучения 
В качестве обобщения укажем на суть научного мышления. Прежде всего, речь идет о практической деятельности спортивных менеджеров как основы данного мышления. Моделирование при этом является своеобразным средством достижения запланированных результатов, представленных в виде делового успеха. С позиций структуризации важно выделить:

1) эмпирическое мышление, с помощью которого осуществляется опознание «конкретно-чувственных» объектов и сравнение полученных данных с целью выделения общих признаков физкультурно-спортивной или оздоровительной деятельности;

2) теоретическое мышление, основой которого является «мысленный эксперимент».

С позиций рассматриваемой научной проблемы важно также указать на наличие основных положений диалектико-материалистической теории психологической миниэкономики развивающего обучения спортивных менеджеров в вузе физической культуры.

Обобщая, укажем также на основные темы курса «Теория миниэкономики образования»:

- особенности управления социальными процессами в миниэкономике образования;

- профессиональное образование личности менеджера как объект миниэкономического исследования;

- характеристика субъектов в миниэкономике образования и эффективность их взаимодействия;

- моделирование процессов и систем миниэкономики образования;

- методологические основы, ведущие закономерности и принципы миниэкономики образования.

Теорию, рассматриваемую нами, можно назвать «Современной теорией обучения личности спортивного менеджера». Суть ее заключается в накоплении и объяснении фактов формирования системы миниэкономики образования. Она включает в свой состав понятия, закономерности, принципы, методы и формы организации учебно-познавательной деятельности в вузе. Исследованию подлежат и методологические основы личностно-развивающего обучения будущего спортивного менеджера.

Под обучением при этом понимается систематически организованный процесс взаимодействия, имеющий целью развитие данной личности. При этом - в методологическом пла- не - такое обучение возможно только при условии активного взаимодействия преподавателя и обучающегося в конкретном вузе студента на всех этапах его личностного становления.

\section{Заключение.}

1. Необходимым условием для формирования инновационной экономики является модернизация системы образования, являющейся основой динамичного экономического роста и социального развития общества [1]. Развитие данной системы, намеченное на период до 2030-го года, ориентировано на повышение доступности и качества образования, подготовку квалифицированных кадров, способных быстро реагировать на запросы рынка труда, повышать уровень своей квалификации в течение всей жизни, использовать свои знания, навыки и компетенции, полученные в процессе обучения.

2. В рамках государственной программы развития образования определено несколько направлений. Среди них: модернизация структуры образовательного процесса с целью обеспечения его гибкости и эффективности; оптимизация сети организаций профессионального образования, учитывающей отраслевые особенности; внедрение механизмов прозрачного финансирования и стимулирования конкуренции организаций профессионального образования; продолжение формирования центров профессиональных квалификаций (ресурсных центров); интернационализация российского высшего образования и расширение экспорта российских образовательных услуг. Все большую роль при этом в современных условиях санкционного периода имеет актуализация вопросов позитивного отношения к учету и развитию на новой основе передового опыта российской системы профессионального образования.

3. Именно в этих позиций следует рассматривать вопросы модернизации системы профессионального образования будущих спортивных менеджеров. Актуальным в данном процессе является инновационный сценарий развития вуза физической культуры, поддержанный на макроуровне. Однако, как показано в работе, не менее важным является миниуровень развития обучения спортивных менеджеров в вузе физической культуры.

4. Известен ряд классификаций миниэкономических теорий образования личности спортивного менеджера [2, 3]. Об одной из них и идет речь в данном разделе работы, посвящен- 
ном развивающему обучению в вузе физиче- тия - культурно-исторического и деятельностской культуры. В основе данной - миниэконо- ного. Структурной единицей последнего, как мической - теории лежат положения о ведущей показано в работе, является мыслительное дейроли экспериментального обучения в развитии ствие, направленное на преобразование «предмышления будущих спортивных менеджеров с метной ситуации» с целью достижения требуевыделением двух направлений данного разви- мого результата по личностному развитию.

\section{Библиографический список}

1. Давыдов В.В. Проблемы развивающего обучения. Москва. 2004. 288 с.

2. Неверкович С.Д. Экономика образования / С.Д. Неверкович, А.А. Попова. Москва. 2018. 161 с.

3. Попова А.А. Экономика образования. Москва. 2018. 302 с.

4. Попов А.Н. Дидактика и философия спортивного менеджмента. Челябинск. 2018. 197 с.

5. Экономическая психология: социокультурный подход / Под ред. И.В. Андреевой. Санкт-Петербург. 2000. $512 \mathrm{c}$. 